\title{
Introducing enhanced recovery after surgery in a high-volume orthopaedic hospital: a health technology assessment
}

\author{
Francesco Vanni ${ }^{1}$, Emanuela Foglia ${ }^{2}$, Federico Pennestri ${ }^{1 *} \mathbb{D}$, Lucrezia Ferrario ${ }^{2}$ and Giuseppe Banfi ${ }^{1,3}$
}

\begin{abstract}
Background: The number of patients undergoing joint arthroplasty is increasing worldwide. An Enhanced Recovery After Surgery (ERAS) pathway for hip and knee arthroplasty was introduced in an Italian high-volume research hospital in March 2018.

Methods: The aim of this mixed methods observational study is to perform a health technology assessment (HTA) of the ERAS pathway, considering 938 procedures performed after its implementation, by means of a hospitalbased approach derived from the EUnetHTA (European Network for Health Technology Assessment) Core Model. The assessment process is based on dimensions of general relevance, safety, efficacy, effectiveness, economic and financial impact, equity, legal aspects, social and ethical impact, and organizational impact. A narrative review of the literature helped to identify general relevance, safety and efficacy factors, and a set of relevant sub-dimensions submitted to the evaluation of the professionals who use the technology through a 7-item Likert Scale. The economic and financial impact of the ERAS pathway on the hospital budget was supported by quantitative data collected from internal or national registries, employing economic modelling strategies to identify the amount of resources required to implement it.
\end{abstract}

Results: The relevance of technology under assessment is recognized worldwide. A number of studies show accelerated pathways to dominate conventional approaches on pain reduction, functional recovery, prevention of complications, improvements in tolerability and quality of life, including fragile or vulnerable patients. Qualitative surveys on clinical and functional outcomes confirm most of these benefits. The ERAS pathway is associated with a reduced length of stay in comparison with the Italian hospitalization average for the same procedures, despite the poor spread of the pathway within the country may generate postcode inequalities. The economic analyses show how the resources invested in training activities are largely depreciated by benefits once the technology is permanently introduced, which may generate hospital cost savings of up to 2054,123.44 € per year.

Conclusions: Galeazzi Hospital's ERAS pathway for hip and knee arthroplasty results preferable to traditional approaches following most of the HTA dimensions, and offers room for further improvement. The more comparable practices are shared, the before this potential improvement can be identified and addressed.

Keywords: Enhanced recovery after surgery, Joint-arthroplasty, Activity-based analysis, Health technology assessment, EUnetHTA, Cost-effectiveness, Value-based healthcare

\footnotetext{
* Correspondence: federico.pennestri@grupposandonato.it

'IRCCS Orthopedic Institute Galeazzi, Via Riccardo Galeazzi 4, 20161 Milan,

Italy

Full list of author information is available at the end of the article
}

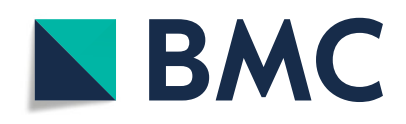

( ) The Author(s). 2020 Open Access This article is licensed under a Creative Commons Attribution 4.0 International License, which permits use, sharing, adaptation, distribution and reproduction in any medium or format, as long as you give appropriate credit to the original author(s) and the source, provide a link to the Creative Commons licence, and indicate if changes were made. The images or other third party material in this article are included in the article's Creative Commons licence, unless indicated otherwise in a credit line to the material. If material is not included in the article's Creative Commons licence and your intended use is not permitted by statutory regulation or exceeds the permitted use, you will need to obtain permission directly from the copyright holder. To view a copy of this licence, visit http://creativecommons.org/licenses/by/4.0/. The Creative Commons Public Domain Dedication waiver (http://creativecommons.org/publicdomain/zero/1.0/) applies to the data made available in this article, unless otherwise stated in a credit line to the data. 


\section{Background}

The spread of chronic musculoskeletal disorders prompted the United Nations, the World Health Organization and 37 countries to proclaim that we are living in the Bone and Joint Decade [1]. The need to provide good quality healthcare at sustainable costs calls for innovative management approaches able to combine effective procedures with efficient allocation of resources.

Improving the value of healthcare became a global priority [2]. At this purpose, the four dimensions of personal, technical, allocative and societal value are being progressively defined by specific indicators of healthcare quality, including clinical, organizational, economic and social implications retrieved from a multidisciplinary and evidencebased health technology assessment (HTA) [3-5].

These efforts are particularly clear in joint arthroplasty (JA), due to high number of procedures delivered worldwide [1]. A number of studies demonstrated how significant improvements in effectiveness and efficiency may not follow from the introduction of a single clinical innovation in the treatment (be it surgical, medical or rehabilitative), but from the way in which the single procedures are related [6-9]. This is the core idea of multidisciplinary accelerated pathways like Fast-Track or Enhanced Recovery After Surgery (ERAS), whose value is maximized by the cooperation between clinical professionals (who offer their expertise on the field) and researchers (who look for best practices and innovations in scientific literature) $[10,11]$.

An ERAS pathway for hip and knee arthroplasty was introduced in a high-volume research hospital, IRCCS Orthopedic Institute Galeazzi (Milan, Italy), in March 2018. The aim of this study is to perform a multidimensional evaluation of the pathway 9 months after its implementation, in order to i) compare benefits and disadvantages with conventional JA, ii) identify subsequent challenges and room for improvement, iii) offer a potential comparison with similar practices worldwide.

\section{Methods}

An HTA is conducted considering 938 hip and knee JAs performed within the ERAS pathway from March to October 2018. The assessment is based on a hospital version [12] of the EUnetHTA Core Model [13], which includes all the dimensions required by the European framework [13]. The following domains were considered and further divided into appropriate sub-dimensions: i) general relevance of the ERAS pathway (the technology under evaluation); ii) safety; iii) efficacy; iv) economic and financial impact; v) equity; vi) legal aspects; vii) social and ethical impact; viii) organizational impact. Each domain is introduced by the most relevant results selected from a narrative review of the literature, performed by seeking the following keywords on PubMed:
"ERAS", "Enhanced Recovery", "Fast Track", "Rapid Recovery", "Arthroplasty", “THA", “TKA", "orthopaedic"; and including only English language manuscripts.

Qualitative, quantitative, or mixed assessments of the technology are performed according to the type of evidence investigated in the single domain. Qualitative assessments of the ERAS pathway are performed through the administration of a 7-item Likert scale validated questionnaire [14] to the 38 healthcare professionals who employ the technology daily (orthopaedic surgeons, anaesthesiologists, physiotherapists, nurses, and supporting staff), who rated their experience from -3 to +3 (the higher the preference, the better the technology). 71\% (27) of these professionals answered the questionnaire. According to the EUNetHTA Core Model, the sample is enough to perform a comparable analysis with other providers [13]. Turning subjective preferences into numerical entities, the Likert scale allows to compare the conventional approach with the ERAS pathway, based on the direct evaluation of the healthcare professionals who employ these technologies daily, and calculate the respective average scores assigned on indicators of interest.

Quantitative assessment is performed by gathering comparable data from 1) internal and/or national registries, such as length of hospital stay (LOS) in acute ward or in rehabilitation setting, and 2) economic analysis tools recommended by the literature. Any comment on the results is postponed to the discussion section. The general relevance of the technology is introduced by a narrative literature review and described more in detail by the comparison between conventional treatment and ERAS pathway, as currently performed within the same hospital.

Focusing on statistical analysis, data were analysed considering descriptive statistics, frequencies, and distributions. After having tested the normal distribution of all the variables investigated $(-1<$ Skewness $<1$ and $1<$ Kurtosis $<1$ ), independent sample t-tests were used to describe the existence of statistically significant differences between the presence or the absence of ERAS pathway, within the qualitative perceptions.

All analyses were conducted with a significance level of 0.05 . Results are expressed as average value \pm standard error.

\section{Results \\ General relevance}

A healthcare technology is relevant when comparable with another existing procedure to treat a significant epidemiological need. JA is considered the best solution against osteoarthritis and rheumatoid arthritis when conservative treatment is not effective, with increasing worldwide patients undergoing surgery primarily due to aging, overweight and trauma $[15,16]$.

In Italy, a dedicated National Register (Registro Italiano Artroprotesi, RIAP) was introduced in 2006 in 
order to collect epidemiological and demographic information associated with patient characteristics from the entire country. According to the last report [17], joint arthroplasties are increasing by $4.1 \%$ per year with a major prevalence of hip (56.3\%) and knee (38.6\%) procedures, following arthrosis as the main diagnosis; the remaining 3.9, 0.3 and $0.9 \%$ surgeries are related to shoulder, ankle and other joints. In 2015, respectively 96.1 and $96.6 \%$ of hip and knee JAs were financed by the Italian National Health Service (Servizio Sanitario Nazionale, SSN), and the trend is expected to increase. For these reasons, any technology able to ensure quality, and improve sustainability is a relevant innovation which could benefit patients, hospitals and funders.

A high variety in patient characteristics, surgeon preferences, logistical arrangements, and regional healthcare financing makes it difficult to compare the approaches adopted by different providers, both in Italy and other European countries [18]. Moreover, more than half of Italian providers are represented by low-volume healthcare institutions, which are generally disadvantaged in implementing effective accelerated pathways $[19,20]$. This is why most of the comparisons between conventional treatment and accelerated pathways are performed within the same healthcare supplier or through beforeafter observational studies [21-23].

The contents of conventional treatment and ERAS pathway as currently provided by Galeazzi Hospital are reported in Table 1.

\section{Safety}

Faster recovery must not preclude safe recovery. Up to $52 \%$ of reduced hospital LOS was obtained without a significant increase in readmissions [24-27], except for old, frail, or psychiatric patients affected by clinical comorbidities could not bear the efforts of enhanced recovery. This occurence will be discussed the domain of equity. Reduced readmissions, complications, transfusions and mortality have been found by comparative studies, reviews and meta-analyses from 1 week to 10 years after surgery [5-35]. An increased risk of urinary tract infections was resolved by gradually abandoning the use of bladder catheters [36]. The incidence of postoperative delirium and cognitive dysfunction was reduced by the introduction of opioid-sparing analgesia [37, 38].

The 938 procedures under assessment included hip and knee, primary and revision, unilateral and bilateral, total and unicompartmental, simultaneous and staged JAs, offering an exhaustive sample of surgical procedures. Eight different surgical teams accepted to adopt the ERAS pathway for all the patients undergoing hip or knee arthroplasty in their unit, without selecting for patient characteristics or type of surgery. Follow-up visits are generally performed after 6 weeks, 3 months, 6 months and 1 year, depending on the surgeon's decision, the evolution of recovery and patient characteristics. Since all the procedures were performed between March and October 2018, at the moment of writing it is impossible to collect data on long-run complications, readmissions, and patient experiences of pain.

The lack of comparative data required preliminary estimations of safety to be carried out by means of a qualitative questionnaire, completed by the 27 healthcare professionals currently employed in the ERAS pathway. According to the EUnetHTA Core Model, they evaluated 9 safety indicators which were largely retrieved from the before-mentioned literature review (Fig. 1).

ERAS pathway dominates conventional treatment on patient safety, reporting a slight improvement in the mean rate $(0.29 \pm 0.011$ vs $0.07 \pm 0.006)$. General security, tolerability, pain, and risk of readmission are the items in which the technology dominates with a difference of more than 0.50 units, calculated by the mean preferences expressed by the professionals through the 7-item Likert Scale. On the contrary, the technology seems not to be equally safe in terms of errors within the procedure, which may trigger risks to the healthcare providers and caregivers which do not comply with a certain innovation introduced within the pathway. However, the mean difference perceived in comparison with the conventional procedure is under 0.50 units.

\section{Efficacy}

Efficacy is different from effectiveness. Efficacy is retrieved from the literature as a parameter of how a certain treatment performs in different settings and/or different patients. Effectiveness is a real-world indicator of how the same treatment performs in a specific setting on specific patients. Then, the efficacy of a certain intervention ("can it work?") is a preliminary condition to test the effectiveness of the same intervention under usual clinical circumstances ("does it work in practice"?) [12, 39].

A number of studies support the efficacy of accelerated pathways. A retrospective comparative study between conventional and accelerated total knee revisions (TKRs) resulted in faster postoperative recovery for those patients who underwent the latter [6]. According to a randomized controlled trial, accelerated TKA resulted in significantly lower knee pain scores and improved functional outcomes 7 days after surgery [32]. An evidence-based review on blood management in Total Joint Arthroplasty (TJA) underlined how accelerated pathways provide useful room for perioperative planning and prediction, generating additional value in comparison to a conventional protocol [9]. A prospective cohort study reported improved function, quality of life, reduced pain, and better Patient-Related Outcome Measurements (PROMs) after accelerated total hip arthroplasty (THA) [40]. Unicompartmental Knee Arthroplasty (UKA) performed under an accelerated 
Table 1 Galeazzi Hospital - Conventional treatment and ERAS pathway

\begin{tabular}{|c|c|c|}
\hline & Conventional (up to February, 2018). & ERAS (from March, 2018). \\
\hline Preoperative. & $\begin{array}{l}\text { Preoperative visit with orthopaedic surgeon and } \\
\text { anaesthesiologist (diagnostic exams included). } \\
\text { Informed consent. }\end{array}$ & $\begin{array}{l}\text { Standard preoperative visit. } \\
\text { 1-h preoperative group education with a physiotherapist and a } \\
\text { nurse, in which details on the pathway are given to the patient in } \\
\text { order to facilitate engagement. } \\
\text { The patient is given life-style advice about the risks of smoking, al- } \\
\text { cohol and bad nutrition in order to maximize postoperative } \\
\text { recovery. } \\
\text { The physical therapist describes the muscle strengthening } \\
\text { exercises to be performed before surgery and the information } \\
\text { which the patient needs to get in advance (crutches, walkers, } \\
\text { elastic stockings, etc.). The social conditions of the patients are } \\
\text { taken into evaluation in order to verify the presence or not of a } \\
\text { caregiver. } \\
\text { In order to reduce preoperative fasting as much as possible, the } \\
\text { patient is given a Carbohydrate loading ( } 2 \text { maltodextrins flasks) } \\
\text { with relative instructions for consumption ( } 1 \text { at midnight before } \\
\text { day of surgery, } 1 \text { at } 6.00 \text { AM the day of surgery). } \\
\text { Blood management (identification and correction of anaemia). } \\
\text { Informed consent. } \\
\text { Pre-emptive oral analgesia. }\end{array}$ \\
\hline
\end{tabular}

Intraoperative. Surgery according to the surgeon's choice. Sub-arachnoid anaesthesia. Drains and catheterization.

Postoperative. Pain management according to the surgeon's choice. Mobilization and physiotherapy from 1 day after surgery, once a day, for half an hour. Pharmacological treatment in case of nausea and vomiting, followed by light dinner or fasting.
Average Average 5.2 days in the acute ward, then

Length of Stay (LOS). a) If the patient does not reach a sufficient level of autonomy, or is not supported by family caregiving: transfer to the rehabilitation unit. Average LOS for rehabilitation: 20 days. b) If the patient reaches a sufficient level of autonomy to face home discharge: direct home discharge.

Perioperative. No audit between the professionals involved in the treatment Dedicated nurses.

Non-dedicated physical therapists (turnover between different wards and procedures).
Tranexamic acid is administered before incision in order to reduce perioperative bleeding.

Tissue-sparing surgery according to the surgeon's choice.

Selective sub-arachnoid anaesthesia in order to maintain vital parameters as stable as possible.

Adductor canal block for total knee arthroplasty (TKA).

Local Infiltration Analgesia (LIA) before surgical suture, if needed, depending on the evaluation of the anaesthesiologist.

Possibly no drains and catheterization.

Multimodal pain management according to the surgeon's choice, including if possible opioid-sparing analgesia.

Postoperative nausea and vomiting prophylaxis.

Feeding $3 \mathrm{~h}$ after surgery, with tea and rusks.

Mobilization 4-6 h after surgery, assisted by 2 physioterapists, once safety conditions are guaranteed by the anaesthesiologist. Assisted walking with crutches.

Light dinner. Pharmacological treatment of nausea and vomiting if needed.

Gastric protection and intestinal prokinetics treatments in order to prevent paralytic ileus.

Two physiotherapy sessions from 1 day after surgery, half an hour each.

a) If the patient is affected by clinical and social conditions of fragility resulting from the preoperative assessment; or by risk factors and complications that emerged later: 3 days LOS in acute orthopaedic ward + internal rehabilitation depending on the need.

b) If the recovery proceeds normally: up to 5 days LOS in acute orthopaedic ward + direct home discharge.

Functional exams are performed depending on the surgeon's choice.

Internal audit (ward data analysis and problem solving) every 4 months.

Dedicated acute ward, physiotherapists and nurses. pathway including minimally invasive surgery, discharge the same day of surgery, and no inpatient physiotherapy reported earlier improvements in knee motion in comparison to a conventional, more invasive approach, equal safety provided [41]. Similar findings were reported by a retrospective observational study on TJAs in a Veteran setting, which concludes how these protocols are essential to support the "transition into an era of value-based arthroplasty" [42].

Accelerated perioperative care and rehabilitation after hip and knee arthroplasty demonstrated good results under different settings and circumstances [42], which provides preliminary evidence of efficiency to investigate the specific degree of effectiveness. 


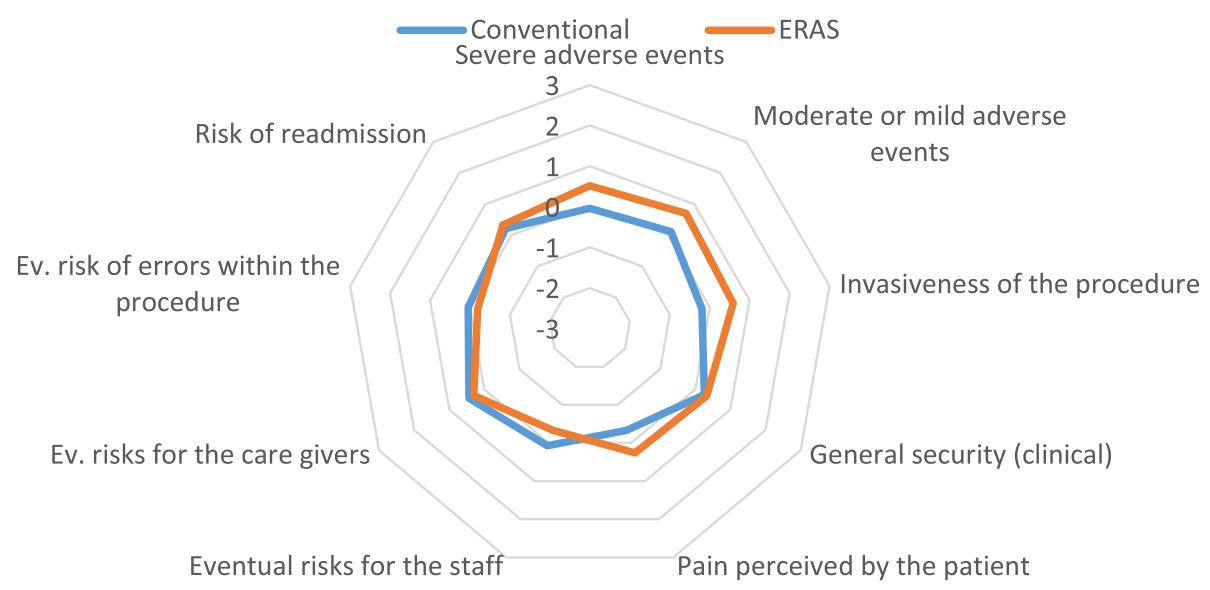

Fig. 1 Safety domain

\section{Effectiveness}

Specific clinical and logistical indicators to assess the effectiveness of accelerated pathways have been identified in maximum 3 days of acute ward LOS, improved patient autonomy and function, positive PROMS, and survivorship after surgery [30, 38].

In the absence of long-term data on patients who underwent surgery in the ERAS pathway, a preliminary estimation of the effectiveness of the technology was performed in three steps.

1) Comparing the average patient LOS in Galeazzi acute and rehabilitation wards (collecting data from the internal registry) with the average LOS in Italian hospitals (collected from RIAP, year 2017), to perform a hip or knee arthroplasty (Table 2). Since RIAP does not allow to distinguish between acute ward and rehabilitation, the overall LOS was considered for comparison. Demographic characteristics such as age and sex are also reported (Table 3).

2) Administering a qualitative questionnaire on 5 indicators of effectiveness [13] retrieved from the before-mentioned literature overview. As long as subjective experiences like pain and PROMS are not available at the time of writing, they are replaced by feedback from individual patients as reported by the staff.

3) Reporting the number of postoperative deaths based on legal complaints.

Table 2 Overall days of LOS, ERAS Galeazzi vs. Italian standard

\begin{tabular}{llll}
\hline Site of surgery. & Italy (RIAP 2017). & ERAS Galeazzi (2018). \\
\hline Hip. & Primary. & 8.1 & $4.2 \pm 0.27$ \\
& Revision. & 13.3 & $4.2 \pm 0.56$ \\
Knee. & Primary. & 7.6 & $4.4 \pm 0.16$ \\
& Revision. & 9.7 & $4.6 \pm 0.61$ \\
\hline
\end{tabular}

The average LOS associated with the ERAS pathway is reduced in comparison to Italian hospitals. Patients undergoing surgery within the pathway are slightly younger and more likely to be males (Fig. 2).

According to the qualitative survey, ERAS dominates the conventional treatment in each of the five indicators, maintaining a difference of more than 0.5 units of preference $(1.90 \pm 0.076$ vs $0.60 \pm 0.095)$. No patients died during hospitalization or after discharge.

\section{Economic and financial impact}

Value is given by healthcare outcomes per dollar spent [43]. Accelerated pathways demonstrated to reduce the cost of arthroplasty up to 1 year-postoperatively [44], resulting cost-effective in different settings [42, 45].

The economic and financial impact of the ERAS pathway was evaluated by adopting the following approaches [46-48].

1) An Activity Based Costing (ABC) [46], in order to compare the cost of the technology under assessment with the previous cost of conventional treatment in the same hospital.

2) A Cost-Effective Analysis (CEA), by means of an Incremental Cost-Effectiveness Ratio (ICER), in order to define the cost-effectiveness ratios generated by conventional treatment and ERAS technology, based on the hospital internal data [48].

3) A Budget Impact Analysis (BIA), calculated from the number of patients treated within the ERAS pathway, multiplied by the cost of the average process, assuming the hospital perspective [47], and considering a 12-month time range, as if the new technology entirely replaced the previous treatment.

All costs are expressed in Euros. 
Table 3 Mean age and sex prevalence, ERAS Galeazzi vs Italian Standard [F (female), M (male)]

\begin{tabular}{llll}
\hline & Italy (RIAP 2017). & & ERAS Galeazzi (2018). \\
\cline { 2 - 3 } & Hip Arthroplasties. & Knee Arthroplasties. & Distinction not available. \\
\hline Mean age. & F 74.7; M 69.2 & F 70.7; M 69.5 $70.1 ;$ M 66.7 \\
Sex prevalence (\%). & F 61.2; M 38.8 & F 67.9; M 32.1 & F 61.9; M 38.1 \\
\hline
\end{tabular}

\section{Activity based costing analysis ( $A B C)$}

The cost of the technology is calculated by the sum of the human and technical resources employed along the process, assuming the hospital perspective (Table 4).

Assuming the hospital perspective, the ERAS pathway costs $€ 34,19$ more than the conventional pathway, where the human resources employed in the preoperative phase represent the main difference.

\section{Cost-effectiveness analysis (CEA)}

Qualitative indicators of effectiveness do not allow rigorous comparisons between similar pathways, and postoperative survivorship is a short-term indicator of effectiveness. Then, an evidence-based comparison between ERAS pathway and conventional treatment can be performed by adopting hospital LOS as a preliminary indicator of the latter (Table 5).

The CEA resulted in -56.98 ICER score, which underlines the greater effectiveness of the ERAS pathway against a moderate economic investment. According to the above, considering an average economic value of a single hospitalization day in Orthopaedic surgery equal to $€ 218.14$, the reduction in LOS will be translated in an economic saving per patient equal to $€ 130.88$ for the hospitalization in Orthopaedic surgery.

\section{Budget impact analysis (BIA)}

Guaranteed the effectiveness and safety of each treatment, the ERAS pathway is associated with reduced patient LOS and increased discharge directly at home.
Considered the average reimbursement of $€ 2244.77$ per patient rehabilitation charged by the hospital to the SSN, the technology under assessment generates significant savings in terms of public healthcare expenditure.

Table 6 compares the amount of public funds spent by the SSN to cover hip and knee arthroplasties under conventional treatment (year 2017) and ERAS pathway.

Assuming the public funder perspective, the analysis shows how the introduction of the new technology saved $€ 688,738.93$ to the SSN in less than 1 year, following from reduced LOS and no need for inpatient rehabilitation. However, this evaluation is performed by comparing 12 months of conventional treatment against 9 months of accelerated pathway. In order to uniform the evaluation, consider the scenario in which the ERAS pathway entirely replaced conventional treatment, 1) assuming the same number of patients (1271) from 1 year to the next; 2) including in detail the following items of healthcare expenditure (Table 7):

1) the cost of admission to orthopaedic surgery (medical costs);

2) the cost of the surgical activity (major surgical procedures);

3) the cost of the rehabilitation activities.

If the ERAS pathway entirely replaced conventional treatment on the same number of patients in 1 year, the technology would generate savings of $€ 2054,123.44$ per year $(-27 \%)$ in comparison to the baseline scenario.

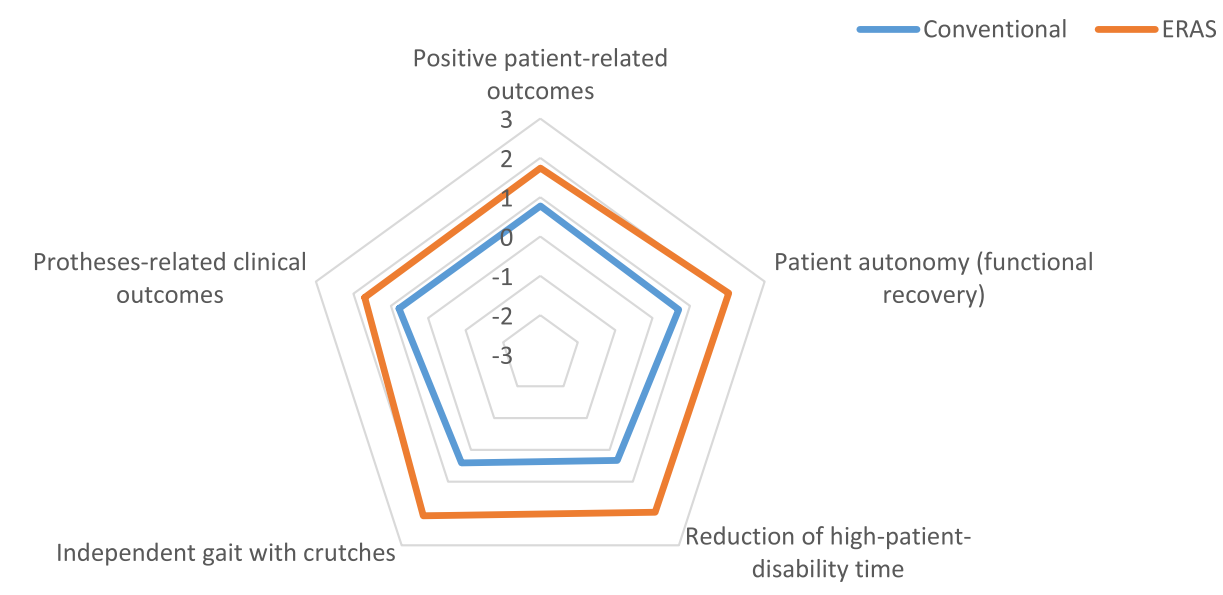

Fig. 2 Effectiveness domain 
Table 4 Activity Based Costing Analysis (€)

\begin{tabular}{|c|c|c|c|c|}
\hline & $\begin{array}{l}\text { Preoperative (per } \\
\text { patient). }\end{array}$ & $\begin{array}{l}\text { Intraoperative (per } \\
\text { patient). }\end{array}$ & $\begin{array}{l}\text { Surgical ward (per day of } \\
\text { hospitalization). }\end{array}$ & $\begin{array}{l}\text { Rehab. (per day of } \\
\text { hospitalization). }\end{array}$ \\
\hline \multicolumn{5}{|c|}{ ERAS Activity Based Costing Analysis. } \\
\hline Human Resources. & 42.00 & 327.80 & 104.00 & 153.90 \\
\hline $\begin{array}{l}\text { Technologies and } \\
\text { equipment. }\end{array}$ & 0 & 24.21 & 16.00 & 16.00 \\
\hline $\begin{array}{l}\text { Drugs, consumables, } \\
\text { prostheses. }\end{array}$ & 7.00 & 1410.64 & 65.52 & 65.52 \\
\hline Other. & 0 & 85.92 & 32.62 & 32.62 \\
\hline Total per each phase. & 49.00 & 1848.52 & 218.14 & 268.75 \\
\hline Total per process. & 2383.75 & & & \\
\hline \multicolumn{5}{|c|}{ Conventional treatment Activity Based Costing Analysis (€). } \\
\hline Human Resources. & 24.00 & 327.80 & 94.10 & 153.90 \\
\hline $\begin{array}{l}\text { Technologies and } \\
\text { equipment. }\end{array}$ & 0 & 24.21 & 16.00 & 16.00 \\
\hline $\begin{array}{l}\text { Drugs, consumables, } \\
\text { prostheses. }\end{array}$ & 0 & 1410.64 & 65.52 & 65.52 \\
\hline Other. & 0 & 85.92 & 32.62 & 32.62 \\
\hline Total per each phase. & 24.00 & 1848.52 & 208,24 & 268.75 \\
\hline Total per process. & 2349.56 & & & \\
\hline
\end{tabular}

Thus, the ERAS accelerated pathway is more affordable than the conventional treatment.

\section{Equity}

The dimension of equity can be distinguished on a macro and a micro level $[49,50]$.

On the macro level, equity is a matter of allocative justice. Achieving the same outcomes with fewer resources (technical value) allows the public funder to free up financial resources which can be reinvested in treating other morbidities, or a higher number of arthritic patients, with a potential reduction in hospital waiting lists, providing better access to free and quality health care (personal, allocative and societal value). In this sense, the economic and financial assessments support equity of the ERAS pathway on a macro level.

On the micro level, equity is a matter of healthcare accessibility to vulnerable categories of patients. Caution must be kept in case of patients who find it difficult to bear early mobilization and intensive rehabilitation, be them psychiatric, old, frail, or affected by other clinical morbidities (i.e. chronic) or conditions of risk. Despite accelerated pathways show improved accessibility to protected categories of patients $[9,51,52]$, their safety remains controversial [53-58].

A qualitative investigation of the equity domain is conducted through 9 indicators retrieved from EUnetHTA Core Model [13] (accessibility of the technology at local level, impact on hospital waiting lists, general inclusivity and ability of the technology to respect the cultural, moral and religious identity of patients) and the beforementioned literature overview (clinical comorbidity and social frailty) (Fig. 3).

The conventional treatment (average value $=0.49 \pm$ 0.0135 ) seemed slightly preferable than the ERAS pathway (average value $=0.33 \pm 0.0172$ ) when analysed in light of the equity domain.

\section{Legal, social, and ethical impact}

The impact of the ERAS pathway from the perspective of society is here declined in terms of i) the human and economic burden removed from the patient and/or his/ her family or caregivers, ii) the estimated productivity loss caused by the attendance of the healthcare environment, iii) the need to support the spread and safety of

Table 5 ICER (€ per day)

\begin{tabular}{lcc}
\hline & Conventional treatment. & ERAS treatment. \\
\hline Cost $(€)$. & 2349.56 & 2383.75 \\
Average LOS in Orthopaedic Surgery (in days). & 5.2 & 4.6 \\
ICER. & $\mathbf{- 5 6 . 9 8}$ & \\
\hline
\end{tabular}


Table 6 Public healthcare expenditure savings following reduced LOS and increased discharge to home $(€)$

\begin{tabular}{lll}
\hline & 2017 (conventional). & March-October 2018 (ERAS). \\
\hline Number of patients. & 1271 & 938 \\
Average LOS in Orthopaedic Surgery. & 5.2 days & 4.6 days \\
Patients \% discharged directly to home. & $12.00 \%(153)$ & $36.14 \%(339)$ \\
Patients \% undergoing inpatient rehabilitation. & $88.00 \%(1118)$ & $63.86 \%(599)$ \\
Average rehabilitation cost per patient. & $€ 2244.77$ & 2244.77 \\
Total expenditure. & $€ \mathbf{2 , 5 1 0 , 7 3 0 . 3 5}$ & $€ \mathbf{1 , 8 2 1 , 9 9 1 . 3 7}$ \\
\hline
\end{tabular}

the technology with adequate legal procedures and market regulation.

Points i) and iii) had been evaluated by the administration of a 7-item Likert Scale qualitative questionnaire to the healthcare professionals answering the questionnaire (Figs. 4 and 5); point ii) had been evaluated by calculating the amount of days spent by the patient in the healthcare environment, including hospital admission and rehabilitation process (Table 6).

Human and social burden removed by the technology (Fig. 4) ERAS pathway dominated the conventional treatment (average value: $1.17 \pm 0.139$ vs $0.59 \pm 0.084$ ) in light of the burden removed by the technology, with the exception of two indicators: economic accessibility to the patient (ability to pay), and social determinants of compliance and technology understanding (i.e. patient language and patient degree of education, health literacy, and consequent ability to comply with the pathway).

\section{Productivity loss}

The perceived reduction of time spent by the patient in the healthcare environment (Fig. 4) is confirmed by the internal hospital register. Table 8 shows how patients who underwent surgery under the ERAS pathway spent on average 4.39 days less in the healthcare environment (surgery and eventual inpatient rehabilitation), in comparison to patients who underwent surgery under the conventional treatment.

Multiplying the average days spent outside the healthcare environment by the number of patients who underwent surgery under the ERAS pathway, in 9 months, the technology saved 4115 days of hospital attendance in comparison to the conventional treatment.

\section{Legal procedures and regulation (Fig. 5)}

Figure 5 shows how ERAS pathway and conventional treatment reach almost equivalent scores (average value: $0.59 \pm$ 0.079 vs $0.58 \pm 0.085$ ) with regards to the legal domain.

\section{Organizational impact}

The sustainability of innovation is given not only from a profitable ratio between costs and benefits, but also from the amount of investments required to replace the previous technology. The potential investments required to implement the ERAS pathway are here described in terms of:

- The percentage of professionals (right column) agreeing or not to perform a certain investment (left column), including potential specific suggestions (Table 9);

Table 7 Total public healthcare expenditure and ERAS-generated saving $(€)$

\begin{tabular}{|c|c|c|}
\hline & 2017 (conventional) & 1-year ERAS \\
\hline Number of patients treated annually for hip and knee JA. & 1271 & $\begin{array}{l}1271 \text { (projection of 100\% ERAS pathway } \\
\text { replacement rate). }\end{array}$ \\
\hline $\begin{array}{l}\text { Average cost of hospitalization to orthopaedic surgery for } 1 \text { patient } \\
\text { (total costs per medical procedure: } € 218.14 \text {, multiplied by average LOS } \\
\text { for conventional procedure: } 9.7 \text { days; and ERAS pathway: } 4.6 \text { ). }\end{array}$ & 2110.50 & 1036.24 \\
\hline Total expenditure for 1 year. & $2,682,445.50$ & $1,317,061.64$ \\
\hline $\begin{array}{l}\text { Average cost of surgery for } 1 \text { patient (total costs to perform a surgical } \\
\text { procedure). }\end{array}$ & 1848.52 & 1848.52 \\
\hline Total expenditure for 1 year. & $2349,468.92$ & $2349,468.92$ \\
\hline Average cost or rehabilitation for 1 patient. & 2244.77 & 2244.77 \\
\hline Number of patients rehabilitated. & $\begin{array}{l}1118 \text { ( } 88 \% \text { of patients admitted } \\
\text { to the conventional treatment). }\end{array}$ & $\begin{array}{l}813 \text { ( } 64 \% \text { of patients admitted to the ERAS } \\
\text { pathway, calculated out of the projection). }\end{array}$ \\
\hline Annual total health care expenditure. & $7,542,644.77$ & $5,488,521.33$ \\
\hline $\begin{array}{l}\text { ERAS pathway-induced savings in case of entire replacement } \\
\text { of the conventional treatment. }\end{array}$ & / & $2054,123.44$ \\
\hline
\end{tabular}




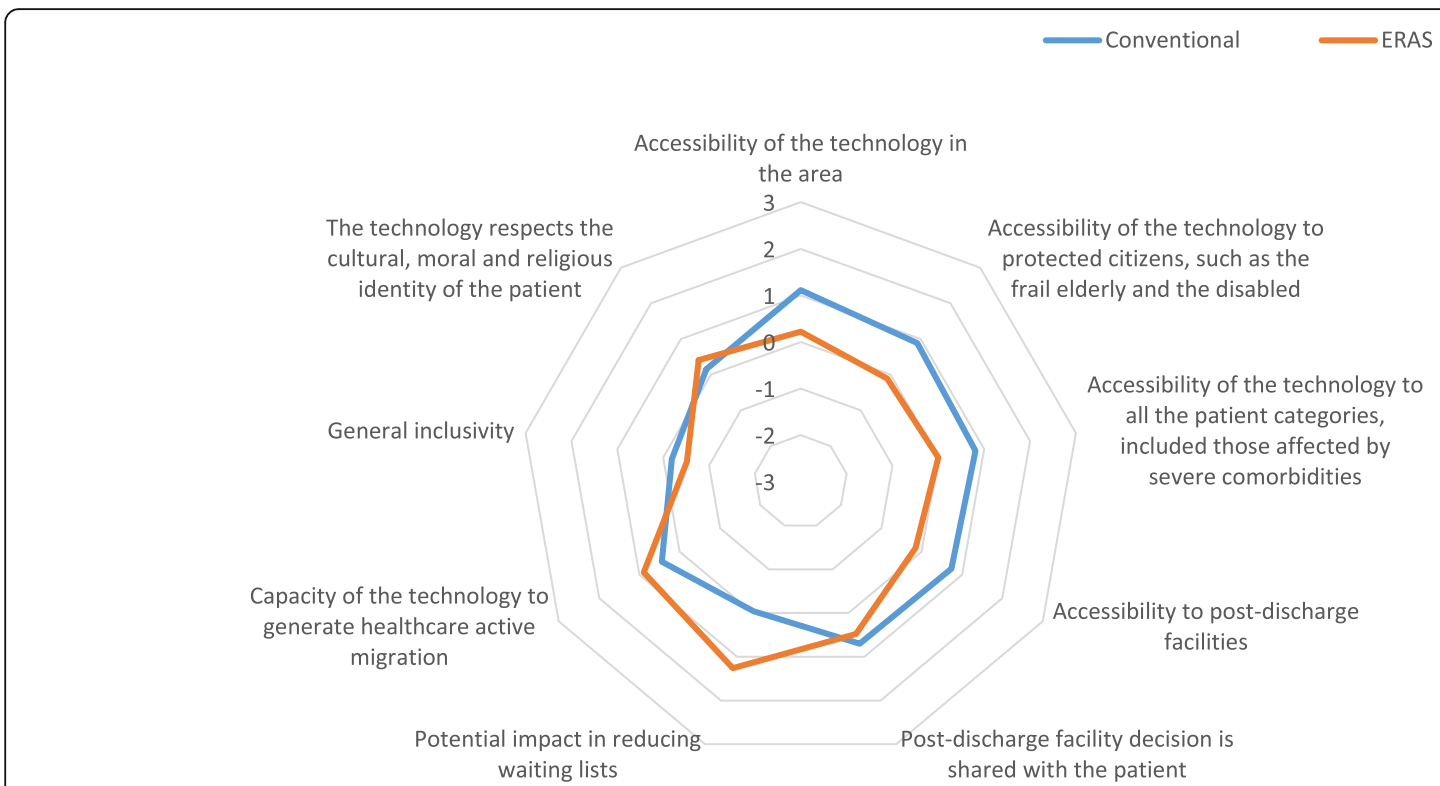

Fig. 3 Equity domain

- The cost of 30-h specific training to all the professionals who employ the technology (Table 10).

The benefits of telemedicine [59], permanent audit [7, $22,34]$ and management technologies [19] are confirmed in the literature. However, adequate professional training courses must be dedicated to all the professionals involved in their use. To estimate the costs of 30-h training activity in the hospital under consideration, the cost per hour of each professional is multiplied by the number of professionals needed in the ERAS pathway, and by the number of training hours.
Introducing a 30-h training activity would require to the hospital an additional investment of $€ 34,480.50$. Considering the $€ 2054,123.44$ estimated savings generated by the introduction of the ERAS pathway in 1 year, the economic investment in training activities should be largely outweighed by the economic benefits induced by the technology.

\section{Discussion}

\section{General relevance}

JA procedures are increasingly performed to treat hip and knee arthritis each year, supported by a number of international studies designed to improve their clinical

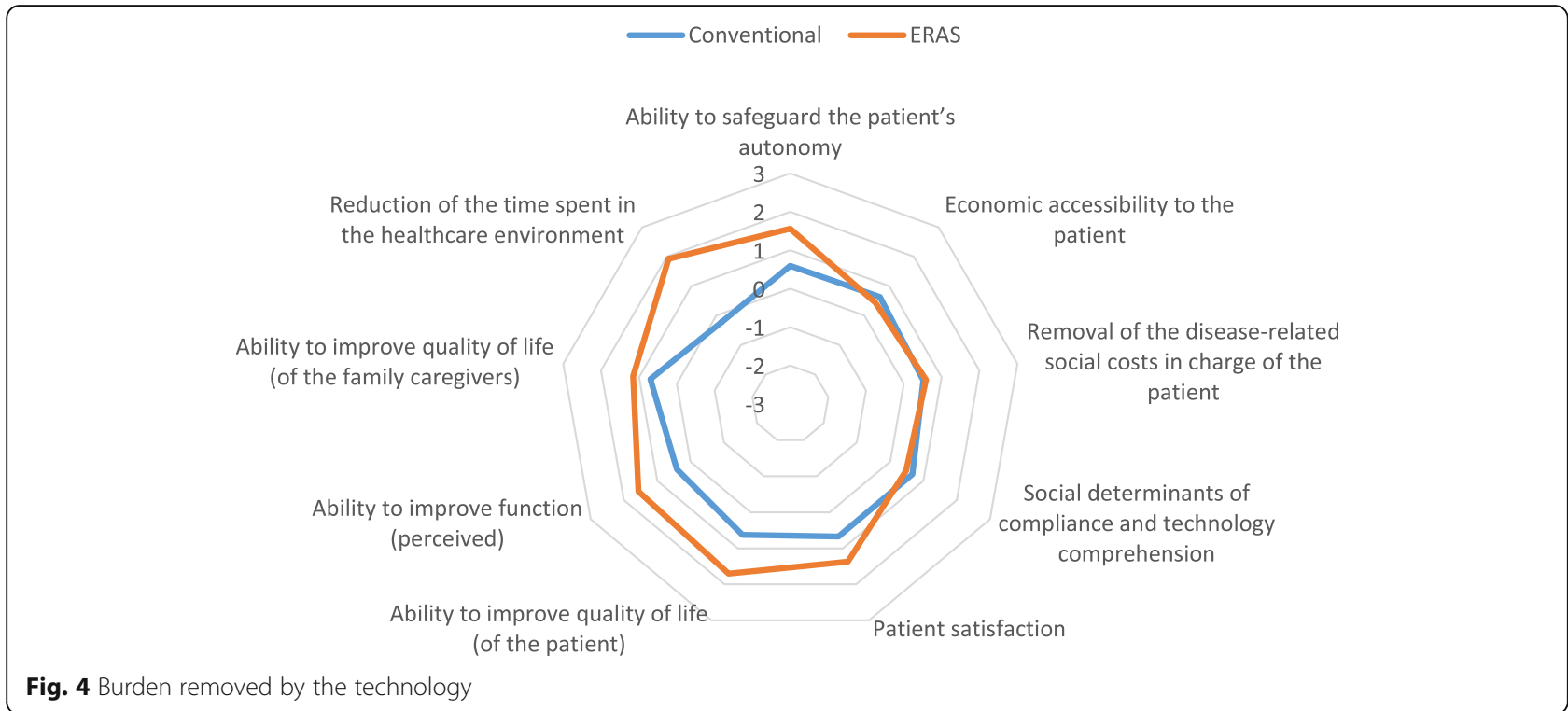




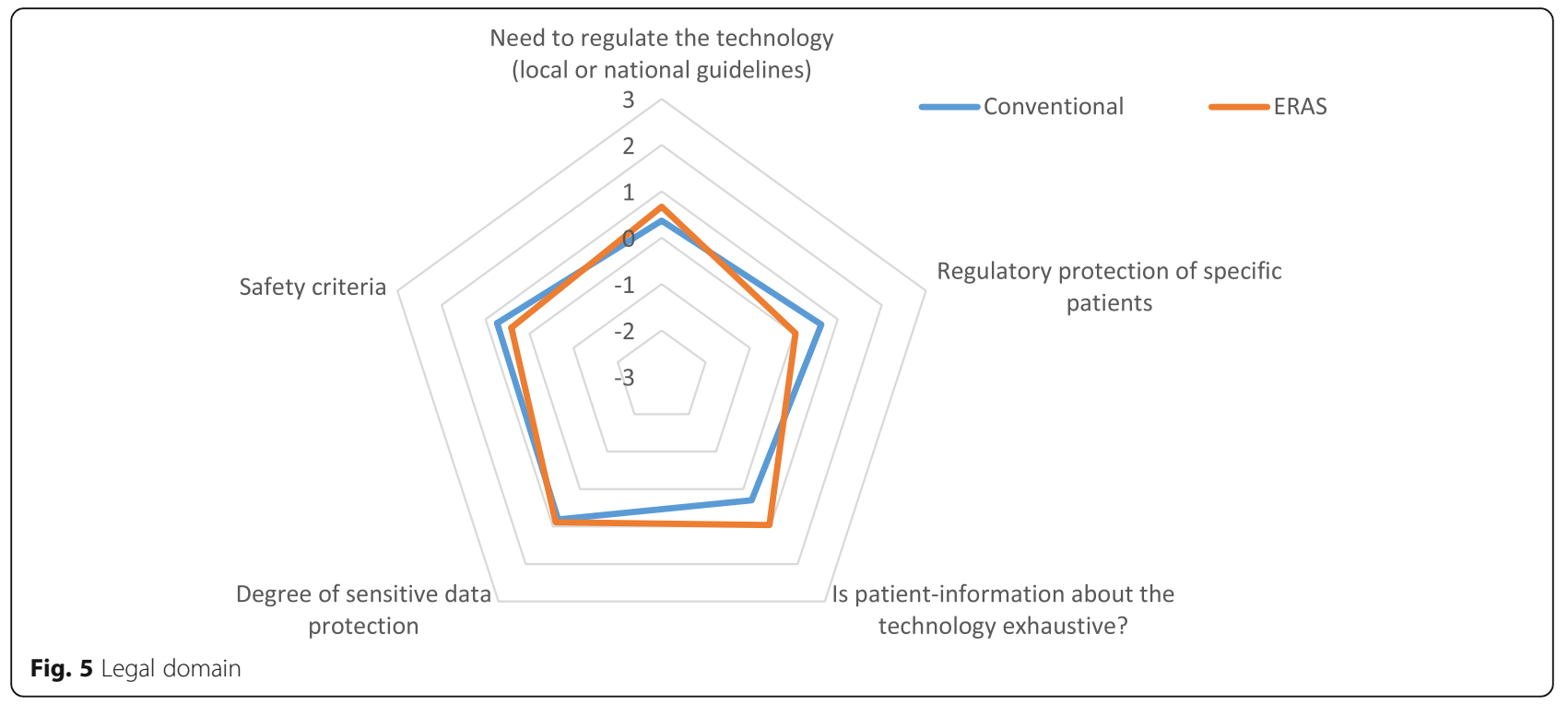

tolerability and financial sustainability. The ERAS pathway introduced in Galeazzi Hospital, which aims to improve the treatment by investing on preoperative planning and perioperative integration of the single medical and surgical performance, can therefore be considered relevant.

\section{Safety}

According to the perception of the professionals involved in the ERAS pathway, the new technology dominates the conventional treatment in terms of general clinical security, tolerability by the patient, reduced pain, and risk of adverse events or readmissions. Improved scores could be explained by the multidisciplinary commitment required by the technology, better communication among the professionals, progress in pain management, and accurate evaluation of the single patient $[6,22,60,61]$. Precautions against urinary trait infections and postoperative delirium, as suggested from the literature [36-38], are adopted within the pathway (i.e. bladder catheter removal and opioid-sparing analgesia whenever possible). On the contrary, the introduction of the new technology may trigger more risks for the professionals who operate within the pathway, since the high level of cooperation which is required may be undermined by perioperative fragmentation. However, specific training and increasing experience are likely to overcome this limit over time. A limit of the present study is the impossibility to measure safety issues from a formal internal registry. However, if considerable adverse events and complications did occur during the pathway, these events would probably have affected the staff ratings, which were performed under conditions of anonymity to avoid bias. Further research may include PROMs in the assessment of this dimension, in order to consider the direct patient's perspective, improve patientoriented care and further reduce potential bias.

\section{Efficacy}

Increasing literature shows accelerated pathways to dominate more conventional approaches in terms of reduced pain scores, earlier functional recovery, improved

Table 8 Time spent in the healthcare environment

\begin{tabular}{lll}
\hline & $\begin{array}{l}2017 \\
\text { (conventional) }\end{array}$ & $\begin{array}{l}2018 \text { March-October } \\
\text { (ERAS) }\end{array}$ \\
\hline Number of patients. & 1271 & 938 \\
\% of which undergoing inpatient rehabilitation. & 88 & 63.86 \\
Average LOS in surgery ward. & 5.2 days & 4.5 days \\
Average days for rehabilitation. & 12.1 & 10.9 \\
Total days spent by total patients in the surgical ward. & 6609.2 & 4221 \\
Total days spent by total patients for rehabilitation. & $13,533.6$ & 6529.2 \\
Total days spent in the healthcare environment. & $20,142.8$ & $10,750.2$ \\
Average days spent inside the healthcare environment for each patient (regardless of rehabilitation & 15.85 & 11.46 \\
or not). & $\mathbf{4 . 3 9}$ & \\
Variation in the average days spent inside the healthcare environment. & &
\end{tabular}


Table 9 Quantitative analysis of the investments required according to ERAS professionals

\begin{tabular}{|c|c|}
\hline Items. & Additional investments required (average). \\
\hline Additional staff. & $\begin{array}{l}\text { 78\% favourable. On average, } 2.8 \text { more nurses, } 2.8 \text { more physical therapists, } 1.9 \text { more social health operators, } 1 \text { case } \\
\text { manager, } 1 \text { internist, } 1 \text { nutritionist, and } 1 \text { dedicated physiatrist were requested. }\end{array}$ \\
\hline Training. & $\begin{array}{l}\text { Specific courses for every professional involved. } \\
1 \text {-h training to the patients and their informal caregivers by a nurse and a physical-therapists when in operation (88.9\%). }\end{array}$ \\
\hline $\begin{array}{l}\text { Communications/ } \\
\text { meetings. }\end{array}$ & Permanent periodic audit (100\%). \\
\hline Spaces and furnishings. & $\begin{array}{l}\text { More space (62.9\%), average } 43 \mathrm{~m}^{2} \text {. } \\
\text { New furniture: a dedicated gym (18.5\%), more PCs, desks and chairs (14.8\%), electric beds (14.8\%), showers (3.7\%). }\end{array}$ \\
\hline $\begin{array}{l}\text { Machinery and } \\
\text { equipment. }\end{array}$ & $\begin{array}{l}\text { Additional Continuous Passive Motion machines (18.5\%); intraoperative traction beds, ultrasounds, Patient-Controlled An- } \\
\text { algesic (PCA) pumps, telemedicine (3.7\%). }\end{array}$ \\
\hline $\begin{array}{l}\text { Management tools and } \\
\text { software. }\end{array}$ & $\begin{array}{l}33.3 \% \text { professionals favourable (inter-operational patient/ward registers, communication between hospital, general } \\
\text { practitioner and rehabilitation facilities). }\end{array}$ \\
\hline
\end{tabular}

quality of life, and better PROMs. This dimension was not supported by a systematic review of the evidence. However, the primary interest of the manuscript is to perform a validated HTA on a specific hospital-based preliminary experience, then the dimension of effectiveness is expected to provide more valuable and substantial information - in comparison to the dimension of efficacy - to share with the clinical and academic community.

\section{Effectiveness}

The technology reduced LOS in comparison to the conventional treatment performed in Italian hospitals. Improved clinical and functional outcomes were reported by the professionals employed within the pathway. The limited time available for data collection and the subsequent impossibility to include PROMs suggest caution in the interpretation of these results. However, longer-lasting clinical studies based on similar outcomes, PROMs included, from 90 days to 10 years after surgery, support positive expectations towards the technology [21, 33, 35, 36, 62-64]. Patients undergoing surgery within the pathway are slightly younger and more likely to be males, although the impossibility to distinguish between hip and knee procedures makes it difficult to investigate the potential determinants of this variation.

\section{Economic and financial impact}

The ABC analysis has estimated that the ERAS pathway costs to the hospital $€ 34.19$ more than the previous, conventional treatment. The incremented cost is mainly due to more investments in human resources at the preoperative phase, in order to provide patient assessment and education. Despite the benefits of pre-operative education for hip and knee replacement are controversial $[65,66]$, current evidence supports the effectiveness of an adequate patient assessment over the perioperative process $[9,51$, 67], which is corroborated by the improved outcomes perceived by the professionals involved in the ERAS pathway. This finding may support the hypothesis that accelerated pathways do not differ from conventional treatment in medical content or surgical technique, but rather from the way in which the perioperative process is planned and integrated, which is probably what makes ERAS pathway a valuable innovation [9].

A moderate additional investment at the preoperative phase is outweighed by a reduction in hospital LOS, which - once the safety of the procedures is maintained - reduces in turn the time spent by the patient in the healthcare environment, generates significant cost savings to the funder, and potentially reduce waiting lists in order to provide a higher number of treatments. The cost-effectiveness of the ERAS pathway is therefore supported by a CEA. It may be argued that reduced hospital LOS is a poor indicator of the effectiveness of a medical

Table 10 Cost of $30 \mathrm{~h}$ specific training to all the professionals employed by the technology

\begin{tabular}{lllll}
\hline Professional. & Hourly cost $(€)$. & Hours. & Units needed in ERAS. & Loss of production $(€)$. \\
\hline Orthopaedic surgeon. & 32.12 & 30 & 15 & $14,454.00$ \\
Anaesthesiologist. & 32.12 & 30 & 10 & 9636.00 \\
Physical therapist. & 15.87 & 30 & 4 & 1904.40 \\
Nurse. & 16.18 & 30 & 15 & 7281.00 \\
Supporting staff. & 13.39 & 30 & 3 & 1205.00 \\
Total cost. & & & $\mathbf{3 4 , 4 8 0 . 5 0}$ \\
\hline
\end{tabular}


treatment, for increased risk of readmissions and increased cost-shifting to the patient may follow. With regard to cost-shifting, ERAS pathway outpatient rehabilitation is provided by Galeazzi Hospital and funded by SSN, without any additional cost to the patient. With regard to readmissions, the lack of long-term data about patient recovery is actually a limit of the present assessment; however, waiting for those data to be available, evidence from longer-lasting studies and positive impressions by the involved professionals support the cost-effectiveness of the ERAS pathway.

Assuming the hospital perspective, projections of oneyear implementation of the ERAS pathway on the same number of patients treated in 2017 under the conventional pathway (as if the technology entirely replaced the previous treatment), generated an estimated saving of $€$ 2054,123.44 per year. Based on these analytical tools, the ERAS pathway is expected to generate positive economic and financial impact. Although the estimations are based on projections on the same number of months and patients, they offer a perspective of the significant economic benefits that the systematic adoption of the ERAS pathway should generate on the long term.

\section{Equity}

According to the professionals involved in the ERAS pathway, the conventional treatment dominates the new technology on 6 out of 9 indicators. Lower outcomes are reported in relation to the accessibility of the technology in the area, the accessibility to post-discharge facilities, and the possibility to choose post-discharge facility together with patient. These results are probably due to the poor spread of the technology outside the hospital: if outpatient rehabilitation requires a specific approach which is compatible with an accelerated pathway, at least in terms of perioperative coordination among professionals, patients who live far from the hospital will find it difficult to obtain adequate support, even more if they are elderly, disabled or frail $[6,39,49,50]$. Lower outcomes are reported also in relation to the general inclusivity of the technology, the accessibility to protected citizens and the accessibility to all patient categories. These results are probably due to the patients who may find it difficult to bear the psychophysical efforts requested by accelerated pathways. However, several studies demonstrate accelerated pathways' improved eligibility to patients older than 85 years or affected by psychiatric disorders or severe comorbidities $[54,68-71]$, although some pathological limits may remain difficult to overcome $[58,72]$. Among the 3 indicators in which the ERAS pathway dominates the conventional treatment, the capacity of the technology to generate active healthcare migration confirms its poor spread outside the hospital. The more the technology proves effective and cost-effective, the more it is likely to be adopted by other health care suppliers and financed by SSN, which would improve the pathway's accessibility and the connection between facilities. These considerations highlight the significant room for improvement offered by the introduction of the ERAS pathway on the dimension of equity, which are expected to improve realistically over time. Further research may include PROMs in the assessment of this dimension, in order to reduce potential bias. Meanwhile, those patients who are not eligible for the pathway may still be enrolled in the conventional treatment, then they are not left untreated.

\section{Legal, social, and ethical impact}

The functional impairment caused by joint pain is a human and economic burden, since quality of life, autonomy and productivity are critically threatened. JA is considered the best solution against osteoarthritis and rheumatoid arthritis when a conservative treatment is not effective. Accelerated pathways present the additional advantage to reduce the time spent within the healthcare environment. However, the new technology seems to present some issues in terms of economic accessibility to the patient and social determinants of compliance. The problem of economic accessibility may occur to patients who need to undergo outpatient rehabilitation compatible with the ERAS pathway. Since such a specific approach may not be provided or funded by the SSN throughout the entire country, the patients who live far from Galeazzi Hospital are likely to pay the service out-of-pocket. The inability of a patient to access equal healthcare based on the area of the country in which he/she was born, or lives, is known in the literature as post-code lottery [50]. Similar to the issues discussed with regard to the domain of equity, this difficulty is likely to be overcome by the increasing spread of accelerated pathways.

With regard to the social determinants of compliance, patients respond to clinical instructions when they are able to understand them, and believe that they will be helpful in solving their problems [73]. Multidisciplinary pathways may be more difficult to understand by socially frail patients, be it for cognitive decline, isolation, language, ethnicity, or education level. Despite patients often appreciate a reduction in hospital LOS [74], they are also worried about being left alone to fragmented healthcare $[75,76]$. In the short term, part of these issues can be resolved by proper patient or family education, which is provided within the ERAS pathway, and it is perceived as exhaustive by the professionals involved ("Is patientinformation about the technology exhaustive?"). In order to take the best advantage from patient education $[65,74$, 77], information must be clear, accessible, and the more patient-centred as possible [78]. In the long term, improved coordination between healthcare institutions and 
dedicated training to the professionals involved may also play a positive role.

With regard to the subdomain of productivity loss, the professionals perceive the ERAS pathway to reduce the time spent in the healthcare environment, as a consequence of reduced hospital LOS and increased discharge directly at home. With regard to the subdomain of legal procedures and regulation, both the conventional treatment and the ERAS pathway need improvements in terms of care providers' compliance to guidelines and patients' data protection. The spread of the new technology, supported by a permanent audit, a multidisciplinary commitment between professionals, clinical feedback, and the share of best practice among researchers, are likely to support this need $[6,46,48]$. Based on these considerations, the ERAS pathway offers room for improvement in terms of legal, social and ethical impact.

\section{Organizational impact}

The economic resources invested in support of professional training activities were estimated to be largely outweighed by benefits once the technology is permanently introduced. Most of the expenditure is likely to occur during the phase of implementation. The more cooperation between the professionals involved in the pathway, hospital governance and administration, the better identification of the organizational issues to be addressed, included the enrollment of dedicated staff. Therefore, the organizational impact of the ERAS pathway is probably sustainable and cost-effective in the long-term.

This HTA involved the commitment of a researcher (not on the payroll) and the support from a few administrative employees (already on the payroll) to access to the data. Therefore, it did not require any additional cost to the hospital. Conversely, clinical, organizational and economic benefits are expected from the improvement of the technology.

\section{Conclusion}

The aim of an HTA is to choose the technology associated to the best "added value" among different alternatives. Value can be conceived in several ways, which include different outcomes, various time ranges and several perspectives. The ERAS pathway under assessment meets most of the considered outcomes and presents considerable room for further improvement. The more experiences are shared and compared, the before this room for improvement can be addressed.

\section{Abbreviations}

ABC: Activity Basted Costing; BIA: Budget Impact Analysis; CEA: CostEffectiveness Analysis; ERAS: Enhanced Recovery After Surgery; HTA: Health Technology Assessment; ICER: Incremental Cost-Effectiveness Ratio; JA: Joint Arthroplasty; LOS: Length Of Stay; PROMs: Patient-Related Outcomes;
RIAP: Registro Italiano Artroprotesi; SSN: Servizio Sanitario Nazionale; THA: Total Hip Arthroplasty; TJA: Total Joint Arthroplasty; TKA: Total Knee arthroplasty; UKA: Unicompartmental Knee Arthroplasty

\section{Acknowledgements}

Not applicable.

\section{Authors' contributions}

FV is responsible of conceptual design; collected quantitative and qualitative data; reviewed the literature; EF is responsible of conceptual design; supervised and contributed to the economic evaluations; FP wrote the manuscript; integrated the literature review; discussed the benefits and limitations of the technology; LF contributed to the economic evaluations; GB supervised the entire contributions. All the authors have read and approved the manuscript.

\section{Funding}

Not applicable.

\section{Availability of data and materials}

Quantitative data were gathered from internal or national registries. Qualitative data were gathered by administering a 7-item Likert scale to 27 the care providers involved in the technology. The National Registry is mentioned in the references. Internal registries and qualitative questionnaires are reserved.

\section{Ethics approval and consent to participate}

Formal ethics approval was not needed. Informed consent was not necessary. National guidelines are available online at http://www. agenziafarmaco.gov.it/sites/default/files/decreto_24062003_inglese.pdf; https://www.gazzettaufficiale.it/eli/id/2019/06/12/19G00059/sg

Consent for publication

Not applicable.

\section{Competing interests}

"The authors declare that they have no competing interests".

\section{Author details}

${ }^{1}$ IRCCS Orthopedic Institute Galeazzi, Via Riccardo Galeazzi 4, 20161 Milan, Italy. ${ }^{2}$ Centre for Health Economics, Social and Health Care Management,

LIUC Business School, LIUC - Università Cattaneo, Corso Matteotti 22, 21053 Castellanza, Varese, Italy. ${ }^{3}$ Vita-Salute San Raffaele University, Via Olgettina 58, 20132 Milan, Italy.

Received: 5 September 2019 Accepted: 6 August 2020

Published online: 24 August 2020

\section{References}

1. Chen A, Gupte C, Akhtar K, Smith P, Cobb J. The global economic cost of osteoarthritis: how the UK compares. Arthritis Epub. 2012;2:698709.

2. Porter ME. What is value in health care? N Engl J Med. 2010;363:2477-81.

3. Pessaux P, Cherkaoui Z. Value-based healthcare: a novel approach to the evaluation of patient care. Hepatobiliary Surg Nutr. 2018;7:125-6.

4. Drummond MF, Schwartz JS, Jönsson B, Luce BR, Neumann PJ, Siebert U, Sullivan SD. Key principles for the improved conduct of health technology assessments for resource allocation decisions. Int J Technol Assess Health Care. 2008:24:244-58.

5. European Commission. Defining value in "Value-based healthcare". Report of the Expert Panel on effective ways of investing in Health (EXPH). (2019) https://ec.europa.eu/health/expert_panel/sites/expertpanel/files/docsdir/ 024_defining-value-vbhc_en.pdf. Accessed 11 Nov 2019.

6. Castorina S, Guglielmino C, Castrogiovanni P, Szychlinska MA, loppolo F, Massimino P, Leonardi P, Maci C, lannuzzi M, Di Giunta A, Musumeci G. Clinical evidence of traditional vs fast track recovery methodologies after total arthroplasty for osteoarthritic knee treatment. A retrospective observational study. Muscles Ligaments Tendons J. 2018;7:504-13.

7. Walters M, Chambers MC, Sayeed Z, Anoushiravani AA, El-Othmani MM, Saleh KJ. Reducing length of stay in Total joint Arthroplasty care. Orthop Clin North Am. 2016:47:653-60. 
8. Kehlet H. Multimodal approach to control postoperative pathophysiology and rehabilitation. Br J Anaesth. 1997;78:606-17.

9. Pennestri F, Maffulli N, Sirtori P, Perazzo P, Negrini F, Banfi G, Peretti GM. Blood management in fast-track orthopaedic surgery: an evidence-based narrative review. J Orthop Surg Res. 2019;14:263.

10. Elhassan A, Ahmed A, Awad H, Humeidan M, Nguyen V, Cornett EM, Urman $R D$, Kaye AD. The evolution of surgical enhanced recovery pathways: a review. Curr Pain Headache Rep. 2018:22:74.

11. Kehlet $\mathrm{H}$, Wilmore DW. Evidence-based surgical care and the evolution of fast-track surgery. Ann Surg. 2008;248:189-98.

12. Foglia E, Lettieri E, Ferrario L, Porazzi E, Garagiola E, Pagani R, Bonfanti M, Lazzarotti V, Manzini R, Masella C, Croce D. Technology assessment in hospitals: lessons learned from an empirical experiment. Int J Technol Assess Health Care. 2017;33:288-96.

13. European network for Health Technology Assessment: European network for Health Technology Assessment. Joint Action on HTA 2012-2015. HTA Core Model User Guide. (2016). https://eunethta.eu/wp-content/uploads/2 018/06/HTACoreModel_UserGuide_Version1.1-1.pdf. Accessed 19 Nov 2019.

14. Mitton C, Dionne F, Damji R, Campbell D, Bryan S. Difficult decisions in times of constraint: criteria based resource allocation in the Vancouver coastal health authority. BMC Health Serv Res. 2011;11:169.

15. Sing JA, Yu S, Chen L, Cleveland JD. Rates of Total Joint Replacement in the United States: Future Projections to 2020-2040 Using the National Inpatient Sample. J Rheumatol. 2019;46(9):1134-40.

16. Ibrahim MS, Twaij H, Giebaly DE, Nizam I, Haddad FS. Enhanced recovery in total hip replacement: a clinical review. Bone Joint J. 2013;95-B:1587-94.

17. Istituto Superiore di Sanità: Registro Italiano Artroprotesi. http://old.iss.it/ riap/. Accessed 1 Jul 2019.

18. Seeber GH, Wijnen A, Lazovic D, Bulstra SK, Dietz G, van Lingen CP, Stevens M. Effectiveness of rehabilitation after a total hip arthroplasty: a protocol for an observational study for the comparison of usual care in the Netherlands versus Germany. BMJ Open. 2017;7:e016020.

19. Greenwald AS, Bassano A, Wiggins S, Froimson MI. Alternative reimbursement models: bundled payment and beyond: AOA critical issues. J Bone Joint Surg. 2016;98:e45.

20. Macario A, Horne M, Goodman S, Vitez T, Dexter F, Heinen R, Brown B. The effect of a perioperative clinical pathway for replacement surgery on hospital costs. Anesth Analg. 1998:86:978-84.

21. Berg $U$, BüLow $E$, Sundberg $M$, Rolfson $\mathrm{O}$. No increase in readmissions or adverse events after implementation of fast-track program in total hip and knee replacement at 8 Sweidsh hospitals: an observational before-and-after study of 14,148 total joint replacements 2011-2015. Acta Orthop. 2018:89:522-7.

22. Husted H. Fast-track hip and knee arthroplasty: clinical and organizational aspects. Acta Orthop Suppl. 2012;83:1-39.

23. Husted HG. Fast track in total hip and knee arthroplasty_experiences from Hvidovre University hospital, Denmark. Injury. 2006;37(Suppl 5):S31-5.

24. Stambough JB, Nunley RM, Curry MC, Steger-May K, Clohisy KC. Rapid recovery protocols for primary total hip arthroplasty can safely reduce length of stay without increasing readmissions. J Arthroplast. 2015;30:521-6.

25. Khan SK, Malviya A, Muller SD, Carluke I, Partington PF, Emmerson KP, Reed MR. Reduced short-term complications and mortality following enhanced recovery primary hip and knee arthroplasty: results from 6,000 consecutive procedures. Acta Orthop. 2014;85:26-31

26. den Hartog YM, Mathijssen NM, Vehmeijer SB. Reduced length of hospital stay after the introduction of a rapid recovery protocol for primary THA procedures. Acta Orthop. 2013;84:444-7.

27. Avalon O, Liu S, Flics S, Cahill J, Juliano K, Cornell CN. A multimodal clinical pathway can reduce length of stay after total knee arthroplasty. HSS J. 2011; 7:9-15.

28. Pamilo KJ, Torkki P, Peltola M, Pesola M, Remes V, Paloneva J. Fast-tracking for total knee replacement reduces use of institutional care without compromising quality. Acta Orthop. 2018:89:184-9.

29. Zhu S, Qian W, Jiang C, Ye C, Chen X. Enhanced recovery after surgery for hip and knee arthroplasty: a systematic review and meta-analysis. Postgrad Med J. 2017;0:1-7.

30. Malviya A, Martin K, Harper I, Muller SD, Emmerson KP, Partington PF, Reed MR. Enhanced recovery program for hip and knee replacement reduces death rate. Acta Orthop. 2011;82:577-81

31. Husted H, Otte KS, Kristensen BB, Ørsnes T, Wong C, Kehlet K. Low risk of thromboembolic complications after fast-track hip and knee arthroplasty. Acta Orthop. 2010;81:599-605.
32. Fransen BL, Hoozemans MJM, Argelo KDS, Keijser LCM, Burger BJ. Fast-track total knee arthroplasty improved clinical and functional outcome in the first 7 days after surgery: a randomized controlled pilot study with 5-year follow up. Arch Ortho Trauma Surg. 2018;138:1305-16.

33. Sharrock NE, Cazan MG, Hargett MJ, Williams-Russo P, Wilson PD Jr. Changes in mortality after total hip and knee arthroplasty over a ten-year period. Anesth Analg. 1995;80:242-8.

34. Barbieri A, Vanhaecht L, Van Herck P, Sermeus W, Faggiano F, Marchisio S, Panella M. Effects of clinical pathways in the joint replacement: a metaanalysis. BMC Med. 2009;7:32.

35. Scott NB, McDonald D, Campbell J, Smith RD, Carey AK, Johnson IG, James $\mathrm{KR}$, Breusch SJ. The use of enhanced recovery after surgery (ERAS) principles in Scottish orthopaedic units -- an implementation and follow-up at 1 year, 2010-2011: a report from the musculoskeletal audit, Scotland. Arch Orthop Trauma Surg. 2013;133:117-24

36. Glassou EN, Pedersen AB, Hansen TB. Risk of readmission, reoperation, and mortality within 90 days of total hip and knee arthroplasty in fast-track departments in Denmark from 2005 to 2011. Acta Orthop. 2014;85:493-500.

37. Krenk $L$, Rasmussen $L S$, Kehlet $H$. Delirium in the fast-track surgery setting. Best Pract Res Clin Anaesthesiol. 2012;26:345-53.

38. Krenk L, Rasmussen LS, Hansen TB, Bogo S, Soballe K, Kehlet K. Delirium after fast-track hip and knee arthroplasty. Br J Anaesth. 2012;108:607-11.

39. Haynes B. Can it work? Does it work? Is it worth it? The testing of healthcare interventions is evolving. BMJ. 1999;319:652-3.

40. Klapwijk LCM, Mathijssen NMC, van Egmond JC, Verbeek BM, Vehmeiher SBW. The first 6 weeks of recovery after primary total hip arthroplasty with fast track. Acta Orthop. 2018;89:140.

41. Munk S, Jensen NJ, Andersen I, Kehlet H, Hansen TB. Early recovery after fast-track Oxford unicompartmental knee arthroplasty. 35 patients with minimal invasive surgery. Acta Orthop. 2012;83:41-5.

42. Yanik JM, Bedard NA, Hanley JM, Otero JE, Callaghan JJ, Marsh JL. Rapid recovery Total joint Arthroplasty is safe, efficient, and cost-effective in the veterans administration setting. J Arthroplast. 2018;33:3138-42.

43. Nwachukwu BU, Hamid KS, Bozic KJ. Measuring Value in Orthopaedic Surgery. JBJS Rev. 2013;1:01874474-201311000-00003.

44. Husted H, Solgaard S, Hansen TB, Sóballe K, Kehlet H. Care principles at four fast-track arthroplasty departments in Denmark. Dan Med Bull. 2010;57: A4166.

45. Larsen $\mathrm{K}$, Hansen TB, Thomsen PB, Christiansen T, Søballe K. Costeffectiveness of accelerated perioperative care and rehabilitation after total hip and knee arthroplasty. J Bone Joint Surg Am. 2009;91:761-72.

46. Akhavan $\mathrm{S}$, Ward L, Bozic KJ. Time-driven activity-based costing more accurately reflects costs in Arthroplasty surgery. Clin Orthop Relat Res. 2016; 474:8-15.

47. Sullivan SD, Mauskopf JA, Augustovski F, Caro J, Lee KM, Minchin M, Orlewska E, Penna P, Rodriguez-Barrios JM, Shau WY. Budget impact analysis_-principles of good practice: report of the ISPOR 2012 budget impact analysis good practice II task force. Value Health. 2014;17:5-14.

48. Chen KK, Harty JH, Bosco JA. It is a brave New World: alternative payment models and value creation in Total joint Arthroplasty: creating value for TJR, Quality and Cost-Effectiveness Programs. J Arthroplasty. 2017;32:1717-9.

49. Daniels N. Just health. Cambridge: Cambridge University Press; 2012.

50. Bognar $\mathrm{G}$, Hirose I. The ethics of healthcare rationing. An introduction. New York: Routledge; 2014.

51. Hansen TB, Bredtoft HK, Larsen K. Preoperative physical optimization in fast track hip and knee arthroplasty. Dan Med J. 2012;59:A4381.

52. Starks I, Wainwright TW, Lewis J, Lloyd J, Middleton RG. Older patients have the most to gain from orthopaedic enhanced recovery programmes. Age Ageing. 2014;43:642-8

53. Goesling J, Moser SE, Zaidi B, Hassett AL, Hilliard P, Hallstrom B, Clauw DJ, Brummett CM. Trends and predictors of opioid use after total knee and total hip arthroplasty. Pain. 2016;157:1259-65.

54. Jørgensen CC, Kehlet H, Lundbeck Foundation Centre for fast-track hip and knee replacement collaborative group. Role of patient characteristics for fast-track hip and knee arthroplasty. Br J Anaesth. 2013;1 10:972-80.

55. Jørgensen CC, Kehlet H, Lundbeck Foundation Centre for Fast-track Hip and Knee Replacement Collaborative Group. Fall related admissions after fasttrack total hip and knee arthroplasty - cause of concern of consequence of success? Clin Interv Aging. 2013;8:1569-77.

56. Jørgensen CC, Kehlet $\mathrm{H}$, Lundbeck Foundation Centre for fast-track hip and knee replacement collaborative group. Outcomes in smokers and alcohol 
users after fast-track hip and knee arthroplasty. Acta Anaesthesiol Scand. 2013;57:631-8.

57. Jørgensen CC, Kjaersgaard-Andersen P, Solgaard S, Kehlet H, Lundbeck Foundation Centre for fast-track hip and knee replacement collaborative group. Hip dislocations after 2,734 elective unilateral fast-track total hip arthroplasties: incidence, circumstances, and predisposing factors. Arch Orthop Trauma Surg. 2014;134:1615-22.

58. Husted H, Jørgensen CC, Gromov K, Kehlet H, Lundbeck Foundation Center for fast-track hip and knee replacement collaborative group. Does BMI influence hospital stay and morbidity after fast-track hip and knee arthroplasty? Acta Orthop. 2016;87:466-72.

59. Vesterby MS, Pedersen PU, Laursen M, Mikkelsen S, Larsen J, Søballe K, Jørgensen LB. Telemedicine support shortens length of stay after fast-track hip replacement. Acta Orthop. 2017;88:41-7.

60. Haugan $K$, Johnsen LG, Basso T, Foss OA. Mortality and readmission following hip fracture surgery: a retrospective study comparing conventional and fast-track care. BMJ Open. 2017;7:e015574.

61. Ansari D, Gianotti L, Schröder J, Andersson R. Fast-track surgery: procedurespecific aspects and future direction. Langenbeck's Arch Surg. 2013;398:29-37.

62. Machin JT, Phillips S, Parker M, Carrannante J, Hearth MW. Patient satisfaction with the use of an enhanced recovery programme for primary arthroplasty. Ann R Coll Surg Engl. 2013;95:577-81.

63. Maempel JF, Clement ND, Ballantyne JA, Dunstan E. Enhanced recovery programmes after total hip arthroplasty can result in reduced length of hospital stay without compromising functional outcome. Bone Joint J. 2016;98-B:475-82.

64. Maempel JF, Walmsley PJ. Enhanced recovery programmes can reduce length of stay after total knee replacement without sacrificing functional outcome at one year. Ann R Coll Surg Engl. 2015;97:563-7.

65. McDonald S, Hetrick S, Green S. Pre-operative education for hip or knee replacement. Cochrane Database Syst Rev. 2004;1:CD003526.

66. Edwards PK, Mears SC, Lowry BC. Preoperative education for hip and knee replacement: never stop learning. Curr Rev Musculoskeletal Med. 2017;10:356-64.

67. Halaszynski TM, Juda R, Silverman DG. Optimizing postoperative outcomes with efficient preoperative assessment and management. Crit Care Med. 2004;32:S76-86.

68. Pitter FT, Jørgensen CC, Lindberg-Larsen M, Kehlet H, Lundbeck Foundation Center for fast-track hip and knee replacement collaborative group. Postoperative morbidity and discharge destinations after fast-track hip and knee Arthroplasty in patients older than 85 years. Anesth Analg. 2016;122:1807-15.

69. Gylvin SH, Jørgensen CC, Fink-Jensen A, Gislason GH, Kehlet H, Lundbeck Foundation Centre for Fast-track Hip and Knee Replacement Collaborative Group. The role of psychiatric diagnoses for outcome Hip and knee arthroplasty. J Arthroplasty. 2017;32:3611-5.

70. Gylvin SH, Fink-Jensen A, Kehlet H, Jørgensen CC, Laursen MB, Gromov K, Schroder HM, Høvsgaard SJ, Wede HR, Kyle PR, Bech P. Prospective psychometric characterization of hip and knee arthroplasty patients. Nord J Psychiatry. 2018;72:39-44.

71. Kehlet $H$, Thienpont E. Fast-track knee arthroplasty - status and future challenges. Knee. 2013;20(Suppl 1):S29-33.

72. Gromov K, Troelsen A, Stahl Otte K, Ørsnes T, Husted H. Morbidity and mortality after bilateral simultaneous total knee arthroplasty in a fast-track setting. Acta Orthop. 2016;87:286-90.

73. Feldman MD, Beckman H, Christensen JF. Difficult patients/difficult situations. In: Feldman MD, Christensen JF, Satterfield JM, editors. Behavioral medicine: a guide for clinical practice. China: McGraw-Hill Education; 2014. p. 30-9.

74. Høvik LH, Aglen B, Husby VS. Patient experience with early discharge after total knee arthroplasty: a focus group study. Scan J Caring Sci. 2018;32:833-42

75. Van Egmond JC, Verburg H, Mathijssen NM. The first 6 weeks of recovery after total knee arthroplasty with fast track. Acta Orthop. 2015;86:708-13.

76. Szöts K, Pedersen PU, Hørdam B, Thomsen T, Konradsen H. Physical health problems experienced in the early postoperative recovery period following total knee replacement. Int J Orthop Trauma Nurs. 2015;19:36-44 Epub 2014 May 2.

77. Wainwright TW, Burgess LC. To what extent do current total hip and knee replacement patient information resources adhere to enhanced recovery after surgery principles? Physyotherapy. 2018;104:327-37.

78. Horstmann H, Colcuc C, Lobenhoffer P, Krettek C, Weber-Spickschen TS. Evaluation of the acceptability of a sphygmomanometer device in knee extension training following surgical procedures of the knee. Int J Orthop Traum Nurs. 2017;25:42-7.

\section{Publisher's Note}

Springer Nature remains neutral with regard to jurisdictional claims in published maps and institutional affiliations.
Ready to submit your research? Choose BMC and benefit from:

- fast, convenient online submission

- thorough peer review by experienced researchers in your field

- rapid publication on acceptance

- support for research data, including large and complex data types

- gold Open Access which fosters wider collaboration and increased citations

- maximum visibility for your research: over $100 \mathrm{M}$ website views per year

At BMC, research is always in progress.

Learn more biomedcentral.com/submissions 